\title{
GESTUALIDADE NAS LÍNGUAS DE SINAIS À LUZ DO PRINCÍPIO SAUSSURIANO DA DUPLA ESSÊNCIA DA LINGUAGEM
}

\author{
Laura Amaral Kümmel Frydrych \\ Submetido em 30 de maio de 2019. \\ Aceito para publicação em 09 de agosto de 2019.
}

Cadernos do IL, Porto Alegre, n. ${ }^{\circ}$ 59, outubro. p. 169-184.

\section{POLÍTICA DE DIREITO AUTORAL}

Autores que publicam nesta revista concordam com os seguintes termos:

(a) Os autores mantêm os direitos autorais e concedem à revista o direito de primeira publicação, com o trabalho simultaneamente licenciado sob a Creative Commons Attribution License, permitindo o compartilhamento do trabalho com reconhecimento da autoria do trabalho e publicação inicial nesta revista.

(b) Os autores têm autorização para assumir contratos adicionais separadamente, para distribuição não exclusiva da versão do trabalho publicada nesta revista (ex.: publicar em repositório institucional ou como capítulo de livro), com reconhecimento de autoria e publicação inicial nesta revista.

(c) Os autores têm permissão e são estimulados a publicar e distribuir seu trabalho online (ex.: em repositórios institucionais ou na sua página pessoal) a qualquer ponto antes ou durante o processo editorial, já que isso pode gerar alterações produtivas, bem como aumentar o impacto e a citação do trabalho publicado.

(d) Os autores estão conscientes de que a revista não se responsabiliza pela solicitação ou pelo pagamento de direitos autorais referentes às imagens incorporadas ao artigo. A obtenção de autorização para a publicação de imagens, de autoria do próprio autor do artigo ou de terceiros, é de responsabilidade do autor. Por esta razão, para todos os artigos que contenham imagens, o autor deve ter uma autorização do uso da imagem, sem qualquer ônus financeiro para os Cadernos do IL.

\section{POLÍTICA DE ACESSO LIVRE}

Esta revista oferece acesso livre imediato ao seu conteúdo, seguindo o princípio de que disponibilizar gratuitamente o conhecimento científico ao público proporciona sua democratização.

http://seer.ufrgs.br/cadernosdoil/index

Terça-feira, 29 de outubro de 2019. 


\title{
GESTUALIDADE NAS LÍNGUAS DE SINAIS À LUZ DO PRINCÍPIO SAUSSURIANO DA DUPLA ESSÊNCIA DA LINGUAGEM
}

\author{
SIGN LANGUAGE GESTUALITY IN THE LIGHT OF \\ THE SAUSSURIAN PRINCIPLE OF THE DOUBLE \\ ESSENCE OF LANGUAGE
}

\author{
Laura Amaral Kümmel Frydrych*
}

\begin{abstract}
RESUMO: O presente artigo objetiva, de um lado, corroborar com a consideração da gestualidade no escopo dos estudos linguísticos sobre as línguas de sinais e, de outro, apresentar e discutir, em relação a ela, o princípio da dupla essência da linguagem proposto por Ferdinand de Saussure. No intuito de sustentar uma abordagem linguística sobre o aspecto gestual, a hipótese na qual se fundamenta este estudo é a de que a gestualidade, considerando o princípio saussuriano da dupla essência da linguagem, possui um duplo estatuto. Assim, a gestualidade pode ser tomada enquanto puro gesto, ou, dito de outro modo, tão somente como um corpo-em-ação, ou enquanto signo linguístico, em seu caráter representacional.
\end{abstract}

PALAVRAS-CHAVE: gestualidade; língua de sinais; Saussure; dupla essência.

ABSTRACT: The present article aims, on the one hand, to corroborate with the consideration of gestuality in the scope of sign languages linguistic studies and, on the other, to present and discuss, in relation to it, the principle of the double essence of language proposed by Ferdinand de Saussure. To support a linguistic approach on the gestural aspect, the hypothesis on which this study is based is that gestuality, considering the Saussurian principle of the double essence of language, has a dual status. Thus, gesture can be taken as a pure gesture, or, in other words, only as a body-in-action, or as a linguistic sign, in its representational character.

KEYWORDS: gestuality; sign language; Saussure; double essence.

\section{Introdução}

O presente artigo está diretamente relacionado com minha pesquisa de doutorado e objetiva, de um lado, corroborar com a consideração da gestualidade no escopo dos estudos linguísticos sobre as línguas de sinais e, de outro, apresentar e discutir, em relação a ela, o princípio da dupla essência da linguagem proposto por Ferdinand de Saussure. No intuito de sustentar uma abordagem linguística sobre o aspecto gestual, a hipótese na qual se fundamenta este estudo é a de que a gestualidade, considerando o princípio saussuriano da dupla essência da linguagem, possui um duplo estatuto. Assim, a gestualidade pode ser tomada enquanto puro gesto, ou, dito de outro modo, tão somente como um corpo-em-ação, ou enquanto signo linguístico, em seu caráter representacional.

\footnotetext{
* Docente na Universidade Federal do Amazonas, doutoranda pelo Programa de Pós-Graduação em Letras da Universidade Federal do Rio Grande do Sul, lauraletraslibras@gmail.com.
} 
Buscando comprovar esse ponto de vista, fundamento a minha discussão, em relação à gestualidade nas línguas de sinais, na abordagem de Viotti e McCleary (2011), principalmente, e, em relação à teorização de Saussure, nos manuscritos intitulados Science du langage, estabelecidos por René Amacker (SAUSSURE, 2011), assim como nos Escritos de Linguística Geral, editados por Bouquet e Engler (SAUSSURE, 2004), retomando ainda algumas noções presentes no Curso de Linguística Geral (SAUSSURE, 2006).

Esta trajetória se compõe de três jornadas. Na primeira, trato das línguas de sinais enquanto línguas no sentido saussuriano do termo, por ser essa a concepção norteadora, neste trabalho, para a mobilização do princípio da dupla essência sobre a noção de gesto. Na segunda parte, retomo algumas das formulações de Saussure sobre a dupla essência da linguagem para aqui deslocá-la a uma distinta materialidade linguística - a gestual. Por fim, na terceira parte, ao abordar a dualidade do aspecto gestual trago um exemplo de fato de linguagem, no qual analiso o funcionamento do princípio da dupla essência, evidenciando, assim, o estatuto linguístico da gestualidade nas línguas de sinais.

\section{Línguas de sinais: sistemas de valores gestuais linguísticos}

Conceber as línguas de sinais como sistemas de valores linguísticos significa levar em conta todas as características desses sistemas, ratificando os princípios que os regem. Em trabalho anterior (FRYDRYCH, 2013), cujo intuito principal foi o de rediscutir o estatuto linguístico das línguas de sinais, tomei por base algumas das noções centrais da linguística saussuriana, quais sejam: o princípio da arbitrariedade - em relação à noção (não saussuriana) de iconicidade - e a noção de valor, bem como a distinção teórica entre linguagem, língua e fala. Destaquei também a apreensão dos signos das línguas de sinais e as possibilidades de sua fixação (via escrita); o caráter linear do significante do signo linguístico, a despeito da simultaneidade de traços visuoespaciais que constituem seus signos; e, enquanto organismo linguístico, ressaltei sua natureza concreta e homogênea, como em qualquer língua natural. As línguas de sinais são línguas, portanto, por serem conjuntos, sistemas de valores linguísticos evidenciados na forma de signos linguísticos (os quais, por sua vez, são formados por unidades materiais e mentais), baseados completamente nas relações desses valoressignos no âmbito do sistema que compõe e, ao mesmo tempo, estão contidos.

Saussure, ao refletir sobre as entidades da língua, explica que a primeira causa que faz da linguagem um objeto que fica fora de qualquer comparação, e não classificado, é a "ausência de linguagens importantes que repousem sobre um outro instrumento, que não a voz, para produzir o signo" (SAUSSURE, 2004, p. 219). Fora do contexto, essa afirmação saussuriana pode causar indignação para aqueles que falam, estudam, e pesquisam uma língua de sinais, cujo instrumento para produzir o signo é, justamente outro, e não está, de fato, na voz (sem que isso, contudo, lhe suprima a importância). Sigamos, por isso, a reflexão de Saussure sobre essa causa:

Com isso, chegou-se a qualificar a linguagem falada de função do organismo humano, misturando, assim, sem volta, o que é relativo à voz e o que é relativo apenas à tradução do pensamento por um signo, que pode ser absolutamente qualquer um e comportar um aperfeiçoamento e uma gramática de acordo com signos visuais ou táteis ou de acordo com signos 
Entendo, com base nessa citação, que Saussure amplia a noção de signo, ao relativizar a concepção de que apenas a voz é significada (tornada signo, concebida como tal), quando situa essa mistura entre o relativo à voz e à tradução do pensamento por um signo. A "tradução do pensamento por um signo", o que podemos chamar de realização da língua, nas palavras do mestre genebrino, "pode ser absolutamente qualquer um", e é notável o fato de ele considerar a potencialidade significante e gramatical de "signos visuais ou táteis". Ou seja, a significação não tem compromisso com a voz, apesar de, historicamente, ter-se considerado significante apenas e tão somente a voz humana ${ }^{1}$. Uma das funções do ser humano é significar, e isso ele o faz via gestualidade, oralidade, e/ou qualquer outro instrumento que manejar e socializar entre seus pares nas interações cotidianas. Isso reforça, portanto, a consideração efetiva das línguas de sinais como "tradução do pensamento", porquanto sígnicas (FRYDRYCH, 2017). Assim, as línguas de sinais são manifestações significantes simbólicas do ser humano, tanto quanto as línguas orais.

A linguista Claudine Normand (2009) afirma que a noção de língua em Saussure abarca um objeto concreto, embora definido abstratamente. Sigo esse entendimento e, por isso, a discussão sobre gestualidade (objeto concreto) presente neste artigo está pautada na concepção saussuriana de língua enquanto sistema de valores (definição abstrata). Esse sistema é o resultado da relação entre os elementos; ele não é tido como uma soma de signos (como se esses fossem estanques, ou prédeterminados), pois isso acarretaria justamente na perda/ausência de valor desses elementos, o qual se dá nas diversas relações no sistema.

Especificamente sobre o signo linguístico das línguas de sinais, é sabido que ele é de natureza visuoespacial, e que sua materialidade é intrínseca à gestualidade. Diferentemente, portanto, da natureza do signo linguístico das línguas orais, em que a materialidade está fundamentada na oralidade, nas línguas de sinais a materialidade significante está na gestualidade. Os pesquisadores McCleary e Viotti (2011) defendem que língua e gesto coexistem nas línguas de sinais, assim como nas orais, e ressaltam que "talvez mais do que nas línguas orais, nas línguas sinalizadas a gestualidade tem um papel central no estabelecimento do léxico e das relações gramaticais, na criação do significado e na organização do discurso" (MCCLEARY; VIOTTI, 2011, p. 290).

Ainda, como bem ressaltam Viotti e McCleary,

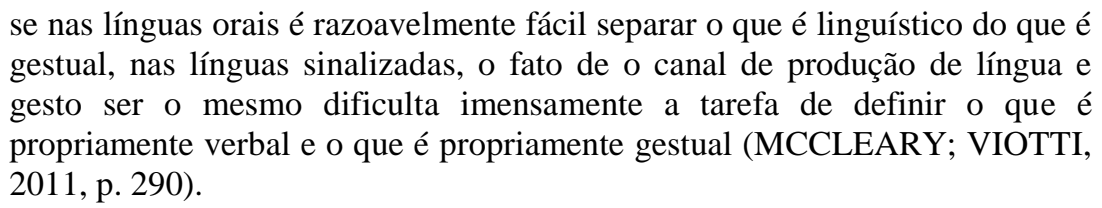

Uma alternativa para essa tentativa de definição (e não necessariamente de oposição, diferenciação entre gestualidade e "verbalidade"), seria a partir de uma abordagem linguística quanto à natureza do signo linguístico, com base na reflexão saussuriana. É o caminho que neste artigo adotarei. A especificidade da gestualidade nas línguas de sinais está em que o aspecto gestual pode ser tomado enquanto puro gesto,

\footnotetext{
${ }^{1}$ Esse entendimento, historicamente, trouxe incalculáveis prejuízos e preconceitos, além de muito sofrimento à comunidade surda, uma vez que sua língua de sinais há muito pouco tempo obteve - e vem reforçando - o reconhecimento de seu status linguístico.
} 
signo "não-linguístico", ou enquanto signo linguístico, como detalharei na sessão a seguir. Assim, a gestualidade, nas línguas de sinais, opera linguisticamente.

Da linguística de base saussuriana tomo ainda como pressuposto básico o fato de que os signos de uma língua são fônicos mas poderiam não ser fônicos, conforme aponta Surreaux (2013, p. 290): "a garantia de existência de um signo linguístico está no fato de que ele produza diferença e oposição dentro de um sistema", e não na constituição material da porção significante desse signo, se vocal/fônica ou gestual, por exemplo. Ou seja, um signo é um signo linguístico quando é diferencial e opositivo dentro de um sistema. Contudo, “(...) para que se possa produzir efeitos contrastivos, precisamos de uma materialidade que carregue e sustente essa diferença" (SURREAUX, 2013, p. 290). Logo, todo signo se funda numa materialidade, mas nem toda materialidade constitui um signo linguístico.

Disso decorre que um signo sempre pode ser outro, pode ser constituído por outra materialidade. Nesse sentido, a gestualidade constitui a base da materialidade das línguas sinalizadas e a mesma se reveste de valor relativamente e no sistema da língua, ou seja, ela é significada, tornada signo linguístico diferencial e opositivo. Assim, os signos das línguas sinalizadas são gestuais e apresentam as características de diferença, relação e oposição no sistema que integram.

Tomo ainda, por fim, como pressuposto o fato de que é a própria língua, sistema significante, que rege o funcionamento articulatório dos nossos órgãos fonadores e "gesticuladores" e isso também pelo princípio das relações negativas que se dão nesse nível material, inclusive, e sempre - redundância dos termos à parte - "percebido pela percepção" dos nossos corpos:

É simples perceber que o movimento não efetivo (não percebido) que se produz na fala é um acessório de unidades efetivas que se realizam a cada momento; sem o que falaríamos para produzir movimentos musculares e não para produzir sons. Por conseguinte, determina-se os movimentos não efetivos quando se consegue representar os efetivos, ou equivalentes a cada unidade audível (SAUSSURE, 2004, p. 218-219).

Essa percepção ${ }^{2}$ aloca uma escuta, e é essa instância de escuta que é condicionante da fala. A oralidade, por meio da voz, é um dentre vários possíveis instrumentos para a significação da linguagem. A gestualidade também é um instrumento para a objetivação do que Saussure aponta como signos visuais, por exemplo, assim como assobios também são signos convencionais escolhidos na voz, como é o caso, por exemplo, da peculiar língua Pirahã ${ }^{3}$. Com isso, a consideração e o

\footnotetext{
${ }^{2}$ Merleau-Ponty, em sua obra Fenomenologia da Percepção, traz, dentre várias interessantíssimas colocações, que "a percepção é um juízo mas que ignora suas razões, o que significa dizer que o objeto percebido se dá como todo e como unidade antes que nós tenhamos apreendido a sua lei inteligível” (MERLEAU-PONTY, 2011, p. 73). Ele também sintetiza que “(...) toda linguagem se ensina por si mesma e introduz seu sentido no espírito do ouvinte” (MERLEAU-PONTY, 2011, p. 244).

${ }^{3}$ A língua Pirahã é uma língua indígena da família linguística Mura, e é falada em uma comunidade no Amazonas. Descrita como tonal, "caracteriza-se por lançar mão de recursos supra-segmentais (a relação entre os tons) para estabelecer significados. Assim, os Pirahã podem, a partir dos tons, gerar modos de comunicação específicos: por meio de gritos, assobios, "falar-comendo". O grito permite a comunicação a grande distância e, em geral, é usado nas conversas travadas quando estão navegando em uma ou mais canoas pelo rio. A comunicação por meio de assobios ocorre em expedições na mata ou no rio, quando as vozes poderiam colocar em risco o objetivo da expedição. Everett (1983) registrou que os assobios seguem os tons, e não uma tonalidade padronizada que estabelece um significado. Assim, os Pirahã são capazes de proferir palavras, e mesmo frases, com o recurso dos assobios. O "falar-comendo" é a terceira
} 
estudo de uma língua que repousa sobre um outro instrumento, ou, outra materialidade - a gestualidade - como o é nas línguas de sinais, e seus variados idiomas, contribui para se repensar as diferentes ordens de fenômenos da linguagem, bem como para corroborar o princípio da dupla essência da linguagem.

\section{O princípio saussuriano da dupla essência da linguagem}

Nesta seção, irei retomar algumas das formulações de Saussure sobre a dupla essência da linguagem para, a seguir, deslocá-la a uma distinta materialidade linguística - a gestual. Esse deslocamento se justifica porque, do que temos registrado do pensamento de Saussure, não encontramos menção explícita sobre a gestualidade enquanto significante. Encontramos reflexões sobre a dupla essência em relação ao som, à figura vocal, ao fenômeno vocal. Uma vez que meu ponto de vista se volta para outra materialidade significante de língua, a gestual, interessa-me ver de que maneira o princípio geral da dupla essência pode ser operacionalizado sobre ela, bem como de que forma a consideração da gestualidade na linguagem modifica (ou não) o princípio apresentado por Saussure.

Uma das notas autográficas de Saussure ${ }^{4}$ tem como tema a questão de um "dualismo profundo que divide a linguagem". Elenquei-a como ponto de partida para as minhas reflexões e análises sobre o princípio da dupla essência e posterior deslocamento, visando sustentar uma abordagem linguística à gestualidade. Da comparação entre as duas versões da referida nota saussuriana sobre esse "dualismo profundo", a estabelecida por Bouquet e Engler (SAUSSURE, 2004) nos Escritos de Linguística Geral (doravante ELG), e a estabelecida por Amacker (SAUSSURE, 2011) no Science du Langage, encontro poucas diferenças formais e de conteúdo. Nesse sentido, faço minhas as palavras de Castro (2016), na leitura que faz dos manuscritos saussurianos, em específico da nota numerada como 372/9:

Sem considerar as diferentes escolhas feitas pelos editores no estabelecimento dos respectivos textos - mantendo ou não as hesitações de Saussure -, é possível dizer que não há diferenças significativas de conteúdo entre o original e as edições de Amacker e a de Bouquet e Engler (CASTRO, 2016, p. 58).

Assim, a explicação, em linhas gerais, sobre o princípio do dualismo na nota selecionada, pouco difere numa ou noutra versão. No entanto, as notas e comentários acrescentados por Amacker em sua edição nos permitem enxergar os seguintes aspectos, que a versão dos ELG nem ao menos faz suspeitar:

possibilidade de estabelecer comunicação por meio dos tons; enquanto mastigam, podem continuar conversando" (PIRAHÃ , 2019). Para mais informações sobre essa interessante língua, sugiro o Documentário Língua Pirahã - o Código do Amazonas (2012).

${ }^{4} \mathrm{O}$ corpus saussuriano é composto por uma infinidade de textos, autográficos ou não. O mais conhecido e famoso material não-autográfico saussuriano é o Curso de Linguística Geral. O presente artigo segue a tendência atual das pesquisas de base saussuriana, ao lançar mão principalmente das fontes autográficas já estabelecidas, mas não se restringe, contudo, a uma leitura retrospectiva das mesmas, no intuito de também fazer avançar a teoria. Nesse sentido minha pesquisa, da qual este artigo é um primeiro resultado, busca um rumo prospectivo em relação à teoria saussuriana. Para mais detalhes sobre um "Saussure prospectivo", consultar Flores (2017). 
a) Pode-se inferir que Saussure tinha bastante interesse sobre esse dualismo, do contrário não teria anotado "para manter" (a conserver) a reflexão que empreende em seguida. Esse registro (cf. nota de rodapé $\mathrm{n}^{\circ} 18$, in SAUSSURE, 2011, p. 86) é explicitado como uma das mais de 390 divergências de seu trabalho que Amacker elenca em relação aos ELG como um todo, na Introdução de seu Science du Langage (SAUSSURE, 2011, p. 39).

b) Saussure, conforme a nota de rodapé $n^{\circ} 3$ contendo uma frase suprimida mostra, parecia suspeitar de que esse dualismo profundo gera "efeitos inesperados" (SAUSSURE, 2011, p. 87); justamente porque a frase foi suprimida, não podemos saber a que efeitos ele se referia;

c) Ao explicar onde reside o dualismo, em dois trechos a flutuação terminológica de Saussure para lidar com esse aspecto é evidenciada: 1) ao "fenômeno vocal COMO TAL", ele suprime a expressão "como fato", talvez porque em seguida irá utilizar esse mesmo termo para designar os aspectos "físico" do som e "mental" da significação - ambos fatos (cf. nota de rodapé 4); e 2) ao abordar o fato subjetivo, ele suprime "psíquico" e opta por mental (cf. nota de rodapé 6). Psíquico aparece em seguida, quando Saussure explica os dois domínios, o interior em específico, e o exterior.

Uma vez que não é meu objetivo, neste artigo, fazer uma análise comparativa aprofundada das diferenças e semelhanças entre as duas formas como esse texto manuscrito saussuriano foi estabelecido, não desenvolverei em mais detalhes as observações elencadas acima. Tão somente destacá-las penso já ser o suficiente para mostrar que as leituras e interpretações a um texto manuscrito estabelecido são inúmeras e variadas, e a que aqui trago é apenas mais uma, dentre várias outras possíveis. Destaco ainda que, no que diz respeito à versão estabelecida por Bouquet e Engler, um encaminhamento interpretativo à noção de dualismo é expressada no título da nota, acrescentado, portanto, como o mostram os colchetes, pelos editores: $2 \mathrm{~d}$ [Princípio de dualismo]. Em nenhum trecho deste parágrafo autográfico encontramos a ocorrência do termo "princípio". Contudo, uma vez que Saussure apresenta uma noção - dualismo atrelada à linguagem e suas diferentes ordens de fenômenos - vocal, objetiva, subjetiva - e a distintos domínios - o interno e o externo -, a escolha do termo "princípio" por Bouquet e Engler a essa orquestração nocional explicativa de Saussure não é, a meu ver, incabível. Diria, inclusive, que a senda interpretativa sugerida por ela indica um caminho interessante a ser percorrido: ao dualismo subjaz um princípio.

Finda essa breve introdução às versões da nota selecionada, passo agora à análise de seu conteúdo, ou, como diz Castro (2016, p. 55) a uma "busca no interno das questões levantadas", a qual farei elegendo a versão em língua portuguesa constante nos Escritos de Linguística Geral, de Bouquet e Engler (SAUSSURE, 2004), uma vez que essa versão é a que se encontra publicada e disponível em língua portuguesa ao público brasileiro hoje. A nota registra o seguinte texto: 
perniciosa de concebê-lo. O dualismo reside na dualidade do fenômeno vocal COMO TAL e do fenômeno vocal COMO SIGNO - do fato físico (objetivo) e do fato físico-mental (subjetivo), de maneira alguma do fato "físico" do som por oposição ao fato "mental" da significação. Há um primeiro domínio, interior, psíquico, onde existe o signo assim como a significação, um indissoluvelmente ligado ao outro; há um segundo, exterior, onde existe apenas o "signo" mas, nesse momento, o signo se reduz a uma sucessão de ondas sonoras que merece de nós apenas o nome de figura vocal (SAUSSURE, 2004, p. 24, grifos do autor).

Da primeira frase dessa nota, percebe-se que, para Saussure, a linguagem pode ser concebida, vista, a partir de dualismos. O dualismo "som-ideia" é um deles, mas, de acordo com Saussure, essa maneira de conceber o dualismo é "fácil e perniciosa". Assim, ao tratar do "dualismo profundo que divide a linguagem", ele não está tratando do dualismo "fenômeno vocal - fenômeno mental". O dualismo profundo é concebido em relação ao fenômeno vocal, e à maneira dual, logo complexa, de abordar esse fenômeno.

Saussure menciona, em outro manuscrito, diferentes dualismos frente aos quais a linguagem pode ser abordada. Em "Notas para o curso II", constante também nos ELG, encontramos a seguinte afirmação sobre a "redução da linguagem a dualidades", acompanhada de uma breve exemplificação (inacabada):

2a [Notas para o curso II (1908-1909): Dualidades]

A linguagem é redutível a cinco ou seis DUALIDADES ou pares de coisas.

$[\ldots]$

III. A lei de Dualidade continua intransponível.

Primeiro par, ou dualidade: os dois lados psicológicos do signo.

$[\ldots]$

Segundo par, ou dualidade: indivíduo/massa.

$[\ldots]$

O terceiro par de coisas é constituído pela língua e pela fala (o signo, previamente duplo pela associação interior que ele comporta e duplo por sua existência em dois sistemas, é entregue a uma dupla manutenção).

$[\ldots]$

Dualidade:

Fala | Língua

Vontade Individual | passividade social

Aqui, pela primeira vez, questão de duas Linguísticas.

(SAUSSURE, 2004, p. 258, grifos do autor).

Das cinco ou seis dualidades mencionadas nessa nota, apenas três delas são elencadas, e somente a terceira (a dualidade fala-língua) é desenvolvida um pouco mais (talvez por comportar, ela mesma, outras ordens de dualidades em seu funcionamento a dualidade do signo, dos sistemas, e de sua manutenção). Além dessa nota explícita sobre as dualidades da linguagem, é possível encontrar, a partir de uma rápida consulta ao Index Rerum dos Escritos de Linguística Geral, um total de nove (9) ocorrências para o termo "dualidade", e duas (2) para o termo "dualismo". A maioria dessas ocorrências consta nas notas dos manuscritos reunidos sob o título "Sobre a essência dupla da linguagem" (Acervo BPU 1996), do que podemos inferir que o princípio geral da dupla essência abarca as noções específicas de dualidade e dualismo, ou que essas noções compõem o princípio da dupla essência da linguagem.

Retomando a nota sobre o "dualismo profundo", encontro na leitura que Stawinski (2016) faz dela, uma pertinente interpretação do conceito de forma, na 
abordagem ao som como elemento linguístico. Diz a pesquisadora que

ao estabelecer que o dualismo da linguagem não se dá na relação som-ideia, só vemos reforçar a noção de que som e forma são conceitos bastante distintos. O som não é da alçada da linguística, é o fenômeno vocal COMO TAL, tomado à parte do jogo semiológico. Já o fenômeno vocal COMO SIGNO delimita a entrada do som como elemento linguístico: a partir daí, pode-se considerá-lo como um fenômeno mental. Certamente, esta divisão entre o que é som puro do que é significante só pode ser feita com vistas a compreender estes conceitos. Afinal, a forma só é passível de ser apreendida pela materialidade que lhe serve de representação (STAWINSKI, 2016, p. 61).

Nesse excerto vemos que a pesquisadora estabelece uma distinção entre "som" e "forma". Forma, em Saussure um conceito específico, é um significante linguístico quando sustentado por uma materialidade (a vocal/sonora, por exemplo) e ligado a um significado. Aqui Stawinski argumenta, em concordância com Saussure, que o som é uma materialidade passível de ser significada. Meu intuito, longe de querer discutir sobre o conceito de "forma", é compreender a dualidade do fenômeno vocal, trazida por Saussure, justamente em relação à essa materialidade sonora, para então desloca-la à materialidade gestual.

O esquema abaixo visa ilustrar a dualidade inerente ao fenômeno vocal, mencionada por Saussure em sua nota sobre o dualismo profundo que divide a linguagem:

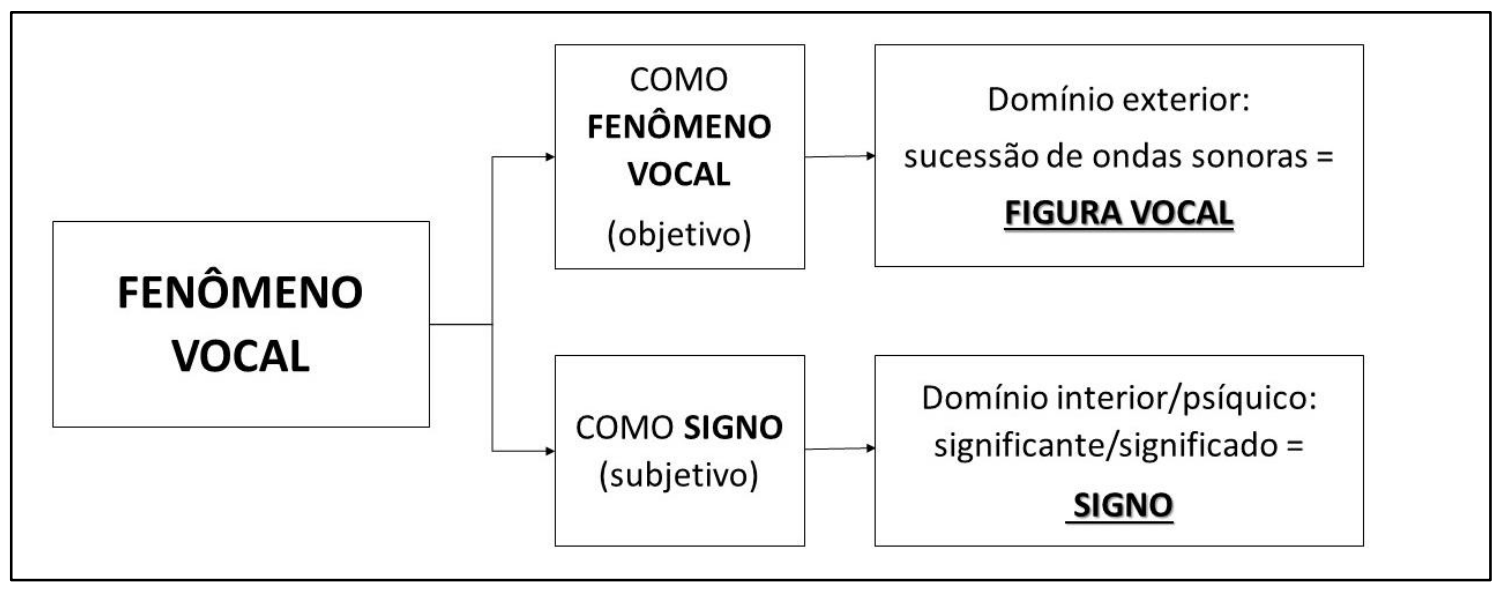

Quadro 1 - Dualidade do fenômeno vocal

Com esse esquema, os dois domínios citados por Saussure ficam bem evidentes: domínio exterior e domínio interior. Uma vez que ele está tratando do dualismo profundo que divide a linguagem, não seria incoerente dizer que os domínios a que ele se refere são domínios da linguagem. Com isso, não estou dizendo que a linguagem seja exterior ou interior ao falante que a mobiliza, não é essa a questão aqui. Ao enfatizar os dois diferentes domínios em relação à linguagem, só faço reforçar sua qualidade, também mencionada no Curso de Linguística Geral, "multiforme e heteróclita; a cavaleiro de diferentes domínios (...)" (SAUSSURE, 2006, p. 17). É a dualidade do fenômeno vocal que possibilita a existência desses dois domínios, nos quais também a linguagem se manifesta. Retornando ao texto da nota, vemos que: 
Há um primeiro domínio, interior, psíquico, onde existe o signo assim como a significação, um indissoluvelmente ligado ao outro; há um segundo, exterior, onde existe apenas o "signo" mas, nesse momento, o signo se reduz a uma sucessão de ondas sonoras que merece de nós apenas o nome de figura vocal (SAUSSURE, 2004, p. 24, grifos meus).

É importante ressaltar que, nesse parágrafo, há três usos diferentes para a palavra "signo", conforme destaquei na citação: 1) em relação ao primeiro domínio, "onde existe o signo assim como a significação, um indissociavelmente ligado ao outro", entendo que "signo" tenha o valor como em outras ocorrências nos manuscritos saussurianos encontramos para "significante", assim, significante e significação (ou significado), no domínio psíquico, interior, estão indissoluvelmente ligados; 2) ao referir o signo no domínio exterior especificamente, Saussure usa aspas junto ao termo; isso pode indicar uma relativização do termo, sugerindo que "signo", no domínio exterior, seja apenas a porção "significante"; 3) complementa Saussure que, aí, "o signo se reduz a uma sucessão de ondas sonoras"; eis a terceira ocorrência do termo signo para designar, nesse caso, o aspecto material, ou o fato físico presente na dualidade. Signo, usado com valor de significante, não é uma exclusividade dessa nota manuscrita, e a luz a esse importante detalhe está aqui a serviço da delimitação da noção de "signo" em distinção à de "figura vocal", que são as noções de "chegada" da nota.

Assim, signo e figura vocal são noções bem diferentes e que estão implicadas no fenômeno vocal, o qual, por sua vez, integra a linguagem. A análise trazida por Stawinski sobre a "identidade" dessa figura vocal é pertinente justamente porque, com ela, é possível distinguir figura vocal de forma linguística, mencionada anteriormente:

Por ser apenas sonoridade pura, a figura vocal tem sempre a mesma identidade, pois existe "independentemente de toda língua" (SAUSSURE, 2004, p. 28). Por isso, dizemos que é desprovida de valor, já que independe de qualquer emprego: "Admitir a forma fora de seu emprego é cair na figura vocal que pertence à fisiologia e à acústica" (SAUSSURE, 2004, p. 33). Quando a figura vocal adentra na esfera do sistema, já não é mais figura vocal: é forma. É o significante do signo linguístico (STAWINSKI, 2016, p. 61).

Para ilustrar a abordagem dual ao fenômeno vocal, Stawinski (2016, p. 48) menciona o fato de que "quando ouvimos uma língua completamente desconhecida, não temos acesso ao som com valor linguístico, mas apenas ao som como fenômeno físico", e porque desconhecemos o significado, o som não é significante, e escutamos apenas uma "sucessão de ondas sonoras". Se, para Saussure, o som, na língua, não tem existência por si mesmo, ou seja, fora da relação de representação que o material sonoro produz no jogo de valores linguísticos (cf. STAWINSKI, 2016, p. 44), pergunto-me se, e em que condições, o gesto, na língua, tem existência por si mesmo. Para isso, passo a examinar o aspecto gestual, à luz das noções subjacentes à dupla essência da linguagem tratadas nesta seção.

\footnotetext{
5 Ao tratar do "signo" como um "conceito escorregadio", Simon Bouquet refere em uma nota que não é raro encontrarmos nos manuscritos saussurianos a ocorrência do termo com duas acepções, e por vezes, no seio de uma mesma frase (BOUQUET, 2000, p. 229). À "flutuação" terminológica em Saussure, quanto a significante $=$ signo, caberia uma investigação mais detalhada. Além de Bouquet (2000), Matsuzawa (2012) e Arrivé (2010) também abordam essa questão. Ressalto, enfim, que, nos manuscritos saussurianos, "signo" muitas vezes significa ou tem o valor de "significante", assim como "significação" significa ou tem o valor de "significado".
} 


\section{A dualidade do fenômeno gestual}

As línguas sinalizadas possuem características miméticas, pictóricas, pantomímicas, além de qualidades formais que permitem sua descrição sistemática. A gestualidade não sistematizada não possibilita a interlocução, o diálogo, a socialização, a vida em sociedade. Ou seja, se se consegue sistematizar movimentos gestuais corporais é porque o sistema permite e também porque a materialidade possibilita. Assim, a potencialidade sistemática linguística está nas relações estabelecidas no âmbito do sistema, bem como na materialidade que as comporta. A materialidade sustenta as diferenças constituídas no e pelo sistema.

Em linguística, materialidade fora de sistema é desprovida de valor, assim como não é concebível um sistema linguístico sem uma materialidade. A dualidade do fenômeno vocal da linguagem, por isso, é tão importante para a reflexão linguística, porque traz a noção de "materialidade", ou de "aspecto material" da língua, para uma função de destaque no jogo de valores. Uma vez que, nas línguas de sinais, a materialidade significante está na gestualidade, é possível deslocar a concepção saussuriana da "dualidade profunda" à modalidade visuoespacial de língua.

A partir dessas considerações, o esquema abaixo visa evidenciar como se dá a dualidade da linguagem em relação ao que denomino então de "aspecto/fenômeno gestual", em que o que era tão somente um corpo-em-ação ${ }^{6}$ passa ao estatuto de significante do signo linguístico:

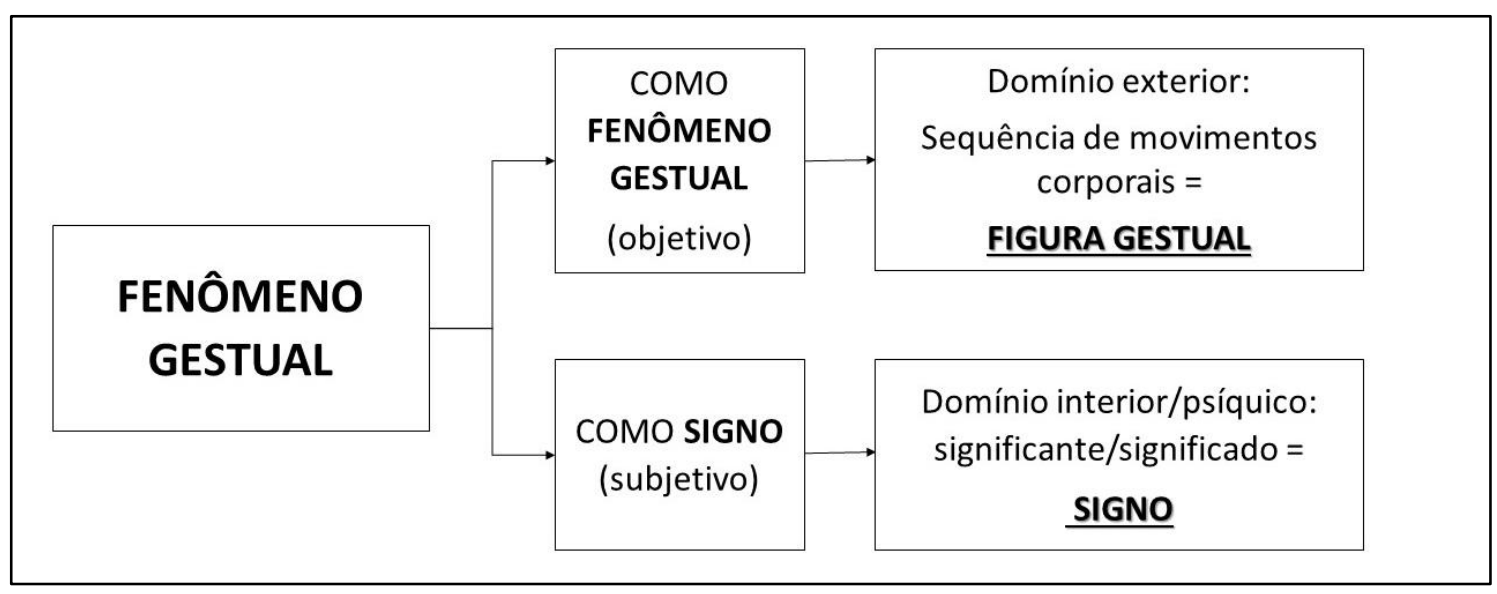

Quadro 2 - Dualidade do fenômeno gestual

Da mesma forma que "o som isolado, fora de qualquer combinação, não pertence à cadeia falada, mas à abstração linguística" (STAWINSKI, 2016, p. 26), assim também nas línguas sinalizadas o movimento corporal, fora de qualquer combinação, não pertence à cadeia falada, mas à abstração linguística. No desenvolvimento da cadeia falada-sinalizada, o que seriam apenas figuras gestuais

\footnotetext{
${ }^{6}$ Lanço mão aqui do termo utilizado por McCleary e Viotti (2017) em estudo onde propõem os fundamentos para uma semiótica de corpos-em-ação, em uma perspectiva cognitivo-interacionista. A perspectiva adotada aqui - linguística de base saussuriana - difere consideravelmente do que apresentam os autores. $\mathrm{O}$ uso do termo neste trabalho reside justamente no valor da porção significante corpo-emação.
} 
combinam-se e resultam em morfemas, sintagmas, sentenças, discurso. Nas línguas sinalizadas, portanto, aquilo de denomina-se comumente de "sinal" é um signo linguístico, cuja porção significante é composta por material gestual, a qual vai estar unida - arbitrariamente - a uma porção de significado.

Evidentemente, há diferentes categorias/tipos de sinais, como, por exemplo, os manuais convencionais (carregados de iconicidade imagética); os dêiticos; os policomponenciais (ou "classificadores"); os não-manuais e também os pantomímicos, conforme apontam McCleary e Viotti (2011). Todavia, é possível tomar todos esses diferentes tipos de sinais, aos quais as descrições teórico-linguísticas visam classificar, como signos linguísticos porquanto a gestualidade está na essência da identidade linguística das línguas de sinais: ela integra o tangível do signo linguístico, além de ser, por si só, material/figura gestual. Assim como ao linguista o som importa apenas em relação ao sistema sincrônico de determinada língua, e não em si mesmo (cf. STAWINSKI, 2016, p. 49), no que diz respeito ao aspecto gestual, cumpre ao linguista analisar o papel que o gesto desempenha no sistema linguístico. Quando estudada por si só, sem relação ao sistema sincrônico da Libras, por exemplo, a gestualidade não interessará ao linguista. Assim, o gesto, na língua, não tem existência por si mesmo, fora da relação de representação que o material gestual produz no jogo de valores linguísticos.

A partir do princípio saussuriano da dupla essência da linguagem depreende-se, portanto, o duplo estatuto do gesto em relação à língua, independentemente da modalidade em relação à qual o gesto seja relacionado - às línguas de sinais ou às línguas orais; o aspecto gestual é dual (assim como o fenômeno vocal), estando o estatuto linguístico implicado nesse princípio. A materialidade sonora é uma das materialidades da língua; não é $a$ materialidade da língua (e a escrita, o registro gráfico, é outra possível materialidade da língua também). Contudo, para os surdos falantes de Libras, por exemplo, o aspecto vocal não é significante da mesma maneira que para os ouvintes, e a materialidade sonora não é delimitável (porque tal materialidade não é tangível como som, ela é tangível a partir da percepção dos movimentos dos lábios dos falantes - ao que se denomina "leitura labial"; a materialidade aí é o corpo, especificamente os lábios). Assim, podemos afirmar que a língua contém o gesto e que o gesto compõe a língua; da mesma forma como a língua contém o som, e o som compõe a língua. Som e gesto, portanto, são duas possíveis materialidades que carregam e sustentam as diferenças no sistema (MILANO, 2015).

Por ser multiforme e heteróclita, a linguagem permite diferentes ordens de valores linguísticos justamente devido ao princípio fundamental que a divide: sua dupla essência. Ao considerar as línguas de sinais como sistema de signos instaura-se mais um paradigma linguístico. Enquanto no sistema das línguas orais-auditivas as relações de negatividade e distintividade são sustentadas pela materialidade vocal, no sistema das línguas visuoespaciais as relações são sustentadas pela materialidade gestual.

Cabe aqui uma observação importante: se ser linguístico se restringisse apenas a ser vocal/fônico ou, se o estatuto linguístico estivesse atrelado exclusivamente à materialidade vocal/oral, uma abordagem em que língua (fundamentada na oralidade) fosse oposta à gestualidade se sustentaria ${ }^{7}$. Em relação ao sistema das línguas orais, o

\footnotetext{
${ }^{7}$ Os pesquisadores McCleary e Viotti (2011) indicam essa distinção, e por vezes mantêm essa oposição. Criticam a linguística formal nesse sentido, por não comportar a gestualidade, ou por excluí-la da teorização. E na conclusão eles apontam a semiótica/cinemática como um dos campos em que haveria espaço para aprofundar a discussão sobre a gestualidade. Essa é uma alternativa para lidar com o
} 
aspecto gestual pode ser considerado complementar/acessório; ou seja, a gestualidade no paradigma do sistema das línguas orais não é fundamental. Por sua vez, uma visão de língua fundamentada na gestualidade comporta a oralidade (ou o aspecto vocal) como acessória; assim, no sistema das línguas de sinais, o fenômeno vocal não é o fundamento. Eis um outro paradigma. Ser sistêmico, ser sígnico, ser relacional, ser opositivo, ser diferencial é o que há de comum em ambos os paradigmas e é o que em ambos constitui o valor linguístico. Disso resulta, contudo, duas ordens singulares de valores.

Nos sinais de uma língua sinalizada há um caráter gestáltico e há um caráter linguístico, conforme McCleary e Viotti (2011). Minha hipótese é de que o linguístico abarca o gestáltico, e isso com base no princípio da dupla essência. Assim como nas línguas orais o fônico/aspecto vocal é tido enquanto tal ou enquanto signo, por semelhante modo, o aspecto gestual nas línguas pode ser tido enquanto tal, ou enquanto signo linguístico. Ao defender a sistematização - necessária - à gestualidade para a existência de uma língua de sinais, quero dizer que a gestualidade é linguística. Assim, cabe dizer que, nas línguas sinalizadas, o gestual é significado na e pela língua em sinais. Já nas línguas orais, o gestual é significado pela língua em gestos. Nas línguas sinalizadas, o aspecto vocal é significado pela língua em movimentos labiais. Nas línguas orais, o fônico é significado na e pela língua em fonemas ou em traços suprassegmentais. Essa consideração da gestualidade e da oralidade em relação tanto ao sistema das línguas orais quanto ao das línguas de sinais é um desdobramento da operacionalização do princípio saussuriano da dupla essência da linguagem, e faz jus, sem dúvidas, a um estudo mais detalhado, uma vez que implica a relação entre diferentes aspectos materiais, em relação a diferentes sistemas linguísticos.

Cabe ainda destacar uma nota de Saussure na qual ele discorre sobre a complexidade das entidades linguísticas em sua inerente dualidade:

(...) não há nenhuma entidade linguística, entre as que nos são dadas, que seja simples porque, mesmo reduzida a sua mais simples expressão, ela exige que se leve em conta, ao mesmo tempo, um signo e uma significação, e que contestar essa dualidade ou esquecê-la equivale diretamente a privá-la de sua existência linguística, atirando-a por exemplo, ao domínio dos fatos físicos (SAUSSURE, 2004, p. 23).

As entidades linguísticas, portanto, podem ter uma "existência linguística" ou não, restando, neste caso, relegadas ao domínio dos fatos físicos, e subsistindo em sua forma de figura vocal/gestual (material), como destacado anteriormente. Para existir linguisticamente, é necessário que a entidade leve em conta, ao mesmo tempo, segundo Saussure, "um signo e uma significação" ". Eis a dualidade incessante: o aspecto material que torna evidente o princípio da negatividade e da distintividade linguísticas não está, contudo, a serviço exclusivo da significação (do signo). A razão de ser do aspecto material está em si mesmo e na forma como é tornado significante. Ou seja, a materialidade pode ou não ser significada em um sistema linguístico. Sendo assim,

fenômeno da gestualidade, contudo, minha proposta é manter e ainda reforçar a discussão sobre a gestualidade no âmbito da ciência linguística, nos moldes de seus próprios pressupostos e princípios, justamente provocando-os, deslocando-os, fazendo-os enxergar e lidar com a materialidade gestual. Dado que a linguagem é multiforme e heteróclita, a linguística é que tem que se refazer considerando outros aspectos além do vocal/fônico.

8 "Signo" aqui compreende o valor de significante, e "significação" o de significado; esse é mais um exemplo da flutuação terminológica percebida a partir dos manuscritos saussurianos. 
depreendemos que há duas maneiras de se tomar a materialidade: em si mesma ou como significante (de um signo). A linguagem se fundamenta, incessantemente, nessa dupla essência: no aspecto material (vocal e/ou gestual) - como tal -, e no aspecto material como signo.

A fim de ilustrar o princípio da dupla essência, que, como exposto até aqui, mobiliza a dualidade do fenômeno físico (vocal/gestual) material, bem como a dualidade intrínseca ao signo linguístico - significante/significado -, trago um exemplo em que o aspecto gestual é visivelmente posto em evidência. Não raro é noticiado pela mídia e veiculado nas redes sociais casos de tradutores-intérpretes de línguas de sinais (TILS) "fakes": pessoas, geralmente sem formação específica na área de tradução e interpretação de línguas de sinais, ou até mesmo sem o conhecimento da própria língua de sinais, que "ousam" atuar como TILS em uma determinada situação (com ou sem a presença da grande mídia para que veicule essa "interpretação").

Um dos casos mais comentados ocorreu no ano de 2013, em torno da atuação de um TILS que fora contratado para atuar no funeral de Nelson Mandela, na África do $\mathrm{Sul}^{9}$. Não demorou muito para se perceber que ele não era um intérprete de "verdade", e que não era qualificado para o trabalho. Ele não estava traduzindo do inglês falado (língua em que a maioria dos discursos eram proferidos) para a língua de sinais sul africana. Ele estava "traduzindo" do inglês falado para gestos, tão somente. Não havia significado nas "entidades linguísticas" que ele expressava. Havia apenas ação manual, pouca ou nula ação corporal, e rara expressão facial; e essas "ações", em relação ao sistema da língua de sinais sul-africana, não comportavam a dualidade; não havia acoplamento de objetos heterogêneos (signos-ideias); não havia, portanto, entidade linguística compartilhada por ele. Era pura figura gestual, e não fatos de linguagem: não havia discurso, e o que se via era tão somente um corpo-em-ação. Daí o consequente vexame de sua atuação "fake".

Trago novamente, para justificar o exemplo mencionado acima, uma citação de Stawinski: "quando a figura vocal adentra na esfera do sistema, já não é mais figura vocal: é forma. É o significante do signo linguístico" (STAWINSKI, 2016, p. 61). Semelhantemente, quando a figura gestual adentra na esfera do sistema, já não é mais figura gestual: é forma. É o significante do signo linguístico gestual. Adentrar na esfera do sistema equivale a ser opositivo, diferencial e negativo em relação aos outros elementos do sistema. Assim, quando um intérprete "fake" gesticula, ele não forma uma cadeia discursiva porque não considera as relações opositivas do sistema (ou, dito de outro modo, ele desconhece o funcionamento do mecanismo e o valor do sistema para o qual está traduzindo). Talvez ele, assim como muitos que ignoram o status e o funcionamento linguístico das línguas de sinais, acredite que, na sinalização, estabelecer uma sequencialidade aos movimentos corporais seja o suficiente para significar (para tornar as figuras gestuais, signos). Como vimos com o princípio da dupla essência, o fato físico do fenômeno vocal/gestual por si só não dá conta da significação. Para significar em LSs, há que, primeiramente, se (re)conhecer os constituintes das figuras gestuais (os chamados "parâmetros"), o que configurará a materialidade "corpo-emação" em uma figura gestual; para que essa figura gestual adentre o sistema, ou seja, para que ela constitua uma forma linguística, é necessário que ela esteja ligada a um significado. E ao falante, ao TILS no caso, cumpre também conhecer o mecanismo de funcionamento do sistema da LS em questão, ou o jogo de valores intrínseco a tal

\footnotetext{
${ }^{9}$ Uma notícia sobre esse TILS e sua atuação no funeral pode ser consultada em Gumuchian (2013).
} 
sistema linguístico de valores gestuais.

\section{Considerações Finais}

Com o exposto até aqui, creio ter conseguido apontar um caminho à consideração linguística sobre a gestualidade. A abordagem saussuriana quanto à dupla essência da linguagem, na forma de suas dualidades, é uma das maneiras de se olhar para o fenômeno gestual, e que integra o gesto à língua, tanto em línguas sinalizadas quanto em línguas orais.

A partir do princípio da dupla essência, posso me ancorar na teoria linguística saussuriana para discorrer sobre as línguas de modalidade visuoespacial, além das oraisauditivas, e das escritas. Ou seja, com base na perspectiva da negatividade sobre o funcionamento do sistema da língua, me valho do pressuposto de que, nas línguas sinalizadas, o gestual é significado no e pelo sistema linguístico em sinais. Assim, todo sinal é um gesto, mas nem todo gesto é um sinal, e a justificativa para tal afirmação está justamente na dualidade incessante, profunda e que divide - e compõe - a linguagem.

Da mesma forma como "não se pode reduzir a língua ao som, nem separar o som da articulação vocal" (SAUSSURE, 2006, p.15), por semelhante modo não se pode reduzir a língua (de sinais) à gestualidade, nem separar o gesto da articulação manual/corporal. Conforme Stawinski (2016), esta interdependência nada mais é do que a relação indispensável entre os aspectos físico e psíquico, concreto e abstrato da língua - questão que se mostra presente em diversas fontes de pesquisa do pensamento do linguista genebrino Ferdinand de Saussure.

Assim, para evidenciar o estatuto linguístico da gestualidade, a perspectiva saussuriana do valor se mostra muito profícua. Este olhar semiológico à língua de sinais implica um olhar que julga, distingue, opõe e identifica o valor a partir da materialidade (cf. STAWINSKI, 2016, p. 106) gestual, sempre em busca do corpo-em-ação como significante. Para quem "vê vozes", "escutar" o gesto é fundamental. Mas essa "escuta" requer um outro caminho, e a presente jornada se encerra por aqui. Se neste artigo abordei o aspecto vocal e o aspecto gestual da língua, meu próximo desafio será pensar a relação entre eles, escutando ainda outro sistema semiológico linguístico: a escrita.

\section{REFERÊNCIAS}

CASTRO, Maria Fausta P. de. Ler os manuscritos saussurianos com o Curso de Linguística Geral. In: FARACO, C. A. O efeito Saussure: cem anos do Curso de Linguística Geral. São Paulo: Parábola, 2016. p. 49-71.

FLORES, Valdir do N. Saussure e Benveniste no Brasil: quatro aulas na École Normale Supérieure. São Paulo: Parábola, 2017.

FRYDRYCH, Laura A. K. O estatuto linguístico das línguas de sinais: a Libras sob a ótica saussuriana. 2013. Dissertação (Mestrado em Letras) - Instituto de Letras, UFRGS, Porto Alegre, RS, 2013. Disponível em: https://www.lume.ufrgs.br/handle/10183/81382. Acesso em: 24 ago. 2018. 
FRYDRYCH, Laura A. K. As línguas de sinais sob a ótica saussuriana. In: PINHEIRO, C.; LIMA, M. H. A. (Orgs.) Diálogos - Saussure e os estudos contemporâneos. Vol. III. Natal: EDUFRN, 2017. p. 93-119.

GUMUCHIAN, Marie-Louise. Interpreter at Mandela memorial a fake, group says. In: CNN International. 2013. Disponível em: https://edition.cnn.com/2013/12/11/world/africa/mandela-memorial-fakeintepreter/index.html. Acesso em: 18 set. 2018.

LÍNGUA PIRAHÃ: O código do Amazonas. Direção de Randall Wood e Michael O’Neill. Austrália: Chris Hilton for Essential Media \& Entertainment, 2012. 1 filme (52 min), son., color. Título original: The Grammar of Happiness.

MCCLEARY, Leland; VIOTTI, Evani. Língua e gesto em línguas sinalizadas. In: Veredas Online. Vol. 1, p. 289-304, jan. 2011. Disponível em: http://www.ufjf.br/revistaveredas/files/2011/05/ARTIGO-212.pdf. Acesso em: 24 ago. 2018.

MCCLEARY, Leland; VIOTTI, Evani. Fundamentos para uma semiótica de corpos em ação. In: FIORIN, J. L. Novos caminhos da Linguística. São Paulo: Contexto, 2017. p. 171-193.

MILANO, Luiza. Fonético e fonológico em Saussure: o lugar do fônico no Curso de Linguística Geral. In: EUTOMIA. Vol. 1, nro 16, p. 245-258, dez. 2015. Disponível em: https://periodicos.ufpe.br/revistas/EUTOMIA/article/view/1945. Acesso em: 24 ago. 2018.

NORMAND, Claudine. Convite à Linguística. São Paulo: Contexto, 2009.

PIRAHÃ. In: Povos Indígenas no Brasil, 2019. Disponível em:

https://pib.socioambiental.org/pt/povo/piraha/803. Acesso em: 17 jul. 2019.

SAUSSURE, Ferdinand de. (1916) Curso de Linguística Geral. 27 ed. São Paulo: Cultrix, 2006.

Escritos de Linguística Geral. São Paulo: Cultrix, 2004.

Science du langage - de la double essence du langage. René Amacker (Ed.). Genebra: Librairie Droz, 2011.

STAWINSKI, Aline V. O aspecto fônico da língua: uma reflexão sobre o lugar do ouvinte na proposta Saussuriana. 2016. Dissertação (Mestrado em Letras) - Instituto de Letras, UFRGS, Porto Alegre, RS, 2016. Disponível em:

https://www.lume.ufrgs.br/handle/10183/140177. Acesso em: 24 ago. 2018.

SURREAUX, Luiza M. O rastro do som em Saussure. In: Nonada: Letras em Revista. Porto Alegre, v. 1, n. 20, p. 285-295, mai.- set. 2013. Disponível em: http://www.redalyc.org/pdf/5124/512451670015.pdf. Acesso em: 24 ago. 2018. 